\title{
The long and winding road: Culture, mutation and generic pedagogy
}

David N. Brown

\section{(2) OpenEdition}

\section{Journals}

\section{Electronic version}

URL: http://journals.openedition.org/asp/4035

DOI: $10.4000 /$ asp.4035

ISSN: 2108-6354

\section{Publisher}

Groupe d'étude et de recherche en anglais de spécialité

\section{Printed version}

Date of publication: 1 December 1994

Number of pages: 89-95

ISSN: 1246-8185

\section{Electronic reference}

David N. Brown, «The long and winding road: Culture, mutation and generic pedagogy », ASp [Online], 5-6 | 1994, Online since 30 November 2013, connection on 21 April 2019. URL : http:// journals.openedition.org/asp/4035; DOI : 10.4000/asp.4035

This text was automatically generated on 21 April 2019

Tous droits réservés 


\title{
The long and winding road: Culture, mutation and generic pedagogy
}

\author{
David N. Brown
}

\section{Culture}

1 While universities and colleges are clearly major agencies for the transmission of cultures, albeit cultures of a certain type, it should not be forgotten that students, when they arrive fresh from the system of Secondary education and the family environment, are not empty cultural vessels. Few of them may be able to read music, few of them may have knowledge of the history of art, few may have read the great classical works of literature, few listen to opera or show interest in modern architecture. When I say "culture" it is not this type of culture I mean. Neither do I mean the culture that characterizes a particular type of ethnic behaviour, although this undoubtedly does play a role in my perception of culture.

2 Culture as I see it here is the set of beliefs and values of an individual. Beliefs about how to do things and the values they generate. Beliefs about how to do things are essential for any action and such beliefs influence the way in which an individual perceives and defines a situation. It is through them that its significance is filtered and it is they that guide his attitude or choice in selecting alternative actions. Within a given group of students one is invariably dealing with this type of culture. Like society as a whole, within a community of students, there are shared beliefs about which goals are most worth pursuing and how they ought to be pursued. This dominant, mainstream culture will integrate the behaviour of most of the individuals within the community, or even all of them at certain times. The interesting factor here is that "dominant" does not necessarily signify a "numerical majority." On another level from this lies the different, or even opposed beliefs of a group of individuals within the community who form a sub-culture. And yet, further down are individualist beliefs that are shared by other members of the community. This might be referred to as an idioculture. 
In the light of this framework it may be possible to interpret learner attitudes towards their goals - i.e. the acquisition of a particular type of knowledge in a particular type of way (this' processes incidentally serves the greater yet insidious design of moulding the individual into a desired standardized shape so that he may automatically fit into whatever slot society has to offer later in adult life). As interpretation of this sort is more likely to be accurate if it is based on first-hand experience, my observations may be considered valid for one type of student only: the trainee engineer in a five-year engineering college, namely ESSTIN. It does seem fair to assume though that similar attitudes will be distinguishable in other engineering colleges or elsewhere.

- He's has gained access to an engineering college (by way of a competitive entry examination). Hence, he sees himself as a member of a privileged class: an elite that will step out of college directly into a well-paid job. As such, he need worry only about academic subjects that characterize that elite.

- He believes that his secondary education is the one of greatest status. ${ }^{1}$

- He believes that learning must necessarily be Cartesian. Knowledge for him consists in stringing the right logical steps out one after the next.

- He believes that learning must be rationalized. He accepts the idea that what has been learned must be tested. He cannot accept, however, the idea that skills are tested rather than knowledge of vocabulary, grammar, direct course content and in general anything that can be learned and revised.

- Teaching not messianic in nature is viewed with suspicion. He believes it to be inefficient.

- He is driven by reward-oriented motivation or at the very least by the threat of punishment. He believes in an abstract short-term goal rather than in the dividend to be had from longterm investment.

- He is the member of a community in which the image one projects of oneself is primordial. This makes him more self-conscious than he normally would be. He believes that respect from others depends on never losing face.

Beliefs such as the ones listed above can be attributed to two sources. Firstly, the curriculum and how it is taught. There can be no doubt that what is taught in schools plays an important role in constructing a pupil's perception of the world: it helps shape his construction of reality and provides him with meanings and legitimations. The second source can be attributed to the social environment in which the trainee engineer has evolved. Constant exposure, on the one hand, to attitudes which lead to the conclusion that the only way through to a fulfilling and successful future is via an engineering education and, on the other hand, the negation of the arts, will generate a construction of reality which will condition the pupil's beliefs and push him along a very peculiar path of interaction with the world. Indeed, this perception of the world and the fact that it is taken for granted is probably the result of informal learning through interaction rather than the result of school education. But it has an important influence on interaction between learner and language teacher.

But why do many people in France still believe that an engineering education is a panacea? Well, most people would consider knowledge of history to be part of "culture", although not the type of culture I am referring to here, whereas knowledge of motorcar mechanics is not. This, of course, is to do with our values and beliefs. But it is probably for historical reasons that the state of affairs I have just described was brought about. After the Revolution in 1789, the French aristocracy had lost much of its status in administration and government, it had also lost much of its money. So, its members had 
to go about making a living. Now, there was not much choice: the army or the clergy. Then, Polytechnique was set up in 1794 in order to supply the technical minds needed for efficient weaponry. The military aristocracy, who were a fairly bright bunch on the whole, made it their own. So engineering in France has been elitist from the outset. Compare this to other countries even as far back as antiquity. The leisured aristocracy in Greece, for example, passed the time discussing politics and ethics. Mathematics was an intellectual activity. Manufacture, agriculture and mining were the occupations of slaves. Therefore, knowledge related to activities like these was considered inferior. Elsewhere in Europe, Greek tradition has been perpetuated through the ages. Thus, the intellectual interests of the social elite have been related to their functions: government, warfare and leisure. Politics, philosophy, literature and music, in a word "the arts" have always been considered as of value to its members, while technology has been excluded. The latter, therefore, is not part of "culture".

The prevailing definition of culture has always been reflected in university curricula. For example, nineteenth century universities in Germany refused to include engineering, while British ones until very recently have been merely the reluctant hosts. Only in France, then, has there been this hiccup in the trend. Engineers are perceived as a social elite and behave accordingly. At ESSTIN, for example, most graduates enter employment on the low managerial level and yet only $2 \%$ of the curriculum is reserved for learning of managerial skills. It is as if the function of engineering education in France is not only to teach special knowledge and skills, but also to transmit, by some form of osmosis, the personal qualities required to manage. This situation is similar to that of the Chinese literati5 who received no training in administration. The literary education they received was believed to confer on the mandarins the special qualities and authority which were essential in an administrator. Clearly then, engineering sciences are perceived as a Superior type of knowledge possessing properties that confer qualities not unlike those of the literati.

7 Until very recently, engineers, including ESSTIN engineers, could walk into any one of four to six job offers immediately after graduation. Confident that work would be easily found, the trainee engineer would ignore not only disciplines not directly connected with his profession, but all other extramural activities and topics. This means that not only did he show very little interest in languages, but when given the opportunity to express himself, he had very little to say, especially as far as the non-technical is concerned. The economic situation has changed since, but there is still a gap between what is and what is believed. In addition, any effort he is prepared to make, must be shrouded in what are seemingly rule-bound activities: grammar, vocabulary lists, error analysis. To him, the developing of communication skills through practice is unconvincing to the point of being outlandish. To this may be added the fact that he can be persuaded to perform on a stick and carrot basis. The promise of extra points (English at ESSTIN counts for four credits) can be an efficient lever. But because it is more difficult to get a high mark in English than in other topics with an equivalent weighting, he is loth to invest the necessary energy (work pressures in other subjects repel him from languages) to guarantee a higher mark in English. He will, however, come to class, frequently because attendance is mandatory and absenteeism is penalized with negative points. Finally, such an environment precludes any approach involving autonomous or self-access learning. A heavy timetable plus other factors previously mentioned here prevent the student from benefiting from such facilities. In fact, students, when given the opportunity to do so (this 
is the case in third and fourth year), will drop out at a rate from around 50\% for the former to $75 \%$ for the latter.

8 Another unavoidable facet in the problem is the age of the student. Young adults have particular problems generated by their transitional and ambiguous role within society, hovering between child and adult status. The environment they have come from and the education system they are in do nothing to accelerate the transition. Although they may be legally adults, students tend to find themselves in a situation where status is ascribed (much like children) while achievements and performance are not judged by the same criteria as in the adult world. This may be because success in an academic environment is seen essentially by those in authority as the mastering of educational skills rather than a real contribution to the community. Strong resentment against the authority in the classroom such as that described by Carter (1962) can result from this and, surprising as it may seem, the situation may be exacerbated when language teachers attempt to place the onus of learning on the student. He may misinterpret this as a lack of commitment on the part of the teacher, especially when she refuses to police the classroom. Moreover, the great gap between the power and authority of the teacher and that of the student accentuates still further the discontinuities between the adult world and that of the child. Finally, the fact that education is extended well beyond the attainment of sexual and legal maturity while delaying social maturity, generates further difficulties.

Under such conditions young adults develop a need to belong to their own communities in which there is emphasis on solidarity. This is why an influential minority lead the remainder so easily. In such groups, the criterion for acceptance, apart from age, is typically expressive activities like sports, dancing, sartorial effect or language. In institutions like ESSTIN the criterion is a certain type of behaviour which might be characterized as "them and us". Participation in this code symbolizes membership and solidarity and again, the language teacher whose background may conduce to greater tolerance and understanding thanks to her background, is a softer target for certain types of student behaviour. But it is via his behaviour that the student achieves a status in the group that replaces other ascribed statuses (family, teachers) which he considers inadequate. This status, however, is by its very nature insecure. Consequently, tolerance of nonconformity is low and lack of cooperation is high. So, the learner who decides to break the code, by say, showing too much cooperation or enthusiasm in the foreignlanguage class is quickly labelled.

\section{Mutation}

In view of the context described above, it seems clear that any effort to forcefeed the student, or to bludgeon him into submission will have the effect of generating more resistance and eventually alienating him as a learner. It has been suggested by specialists in other disciplines that because students are there to work, they should be forced to do so. This may be possible in the so-called essential disciplines like mathematics or physics, because they are perceived as such by students and because such subjects tend to be passive in nature. This is not the case of foreign languages and plainly such strong-armed methods cannot succeed. The result would be a situation similar to that described by sociologists of work wherein the task to be accomplished is external to the person who must accomplish that task. As a result, there is no sense of satisfaction. If the tasks are not voluntary, but imposed, then no specific immediate need is being satisfied. In other 
words, the student experiences little or no self-realization but merely an awareness of a process that leads to an artificial goal: an exam, a mark, an academic requirement.

Conditions such as these are an undeniable source of alienation of which there are four main dimensions: isolation, powerlessness, meaninglessness and self-estrangement (Horowitz 1965). Only the final three apply here.

Powerlessness can be defined as the students inability to control his environment. For example, they are frequent complaints that he is not listened to or consulted. There is a lack of student-teacher communication. Their voice on commissions and councils is merely token and contributes little to influencing decisions and organization, especially on the curriculum level. It has been observed that students frequently ask for what they do not have. One group will, for example, complain that they are not getting enough technical English. If more EST is injected into the syllabus, another group (same age and level of study) at a later period may ask for more general English. The absence of one learning technique is criticized only to be rejected later once it has been made available. These are typical symptoms of powerlessness and are the expression of frustration rather than of genuine desires. They are more frequently directed towards language teachers probably because this is the category which is most likely to lend an ear. and what he perceives as his future professional role. If he is convinced that he will have the services of a bi-lingual secretary then languages are perceived as secondary. More, skills that fall within competences of a subordinate will be perceived as inferior, a relationship that existed between Greek thinkers and slaves (see above). Again subjects like foreign languages are most likely to be affected by this phenomenon in spite of efforts made by teachers to adapt to students demands.

Finally, self-estrangement is the student's failure to see his academic work as a means of self-expression. It is reflected in the separation of this work from his social life. Academic work, and again especially the non-vital subjects, is viewed as being instrumental (a means to an end) rather than a source of intrinsic satisfaction.

15 Alienation, therefore, can be the source of negative mutation wherein a student arriving fresh at the college, and whose attitude was at least open and at worst neutral, quickly develops an apathy for all or most disciplines and vents his frustration on those which present weaknesses like low academic status or low professional necessity. Foreign languages, rightly or wrongly, are frequently perceived to fall within such weaknesses. Negative mutation, therefore, is a threat but not a foregone conclusion especially when' curricula are organized so as to generate positive mutation.

Positive mutation can be brought about by a blend of shock treatment and slow coaxing. The expectations of students must be met while persuading them to adopt new beliefs. When students arrive at ESSTIN they enter a language-learning environment which requires all students to follow the same course irrespective of their level or number of years of study. The course itself is almost totally technical. The effect this has on students is to drive home the fact that they have entered another world. On the one hand, it is a world where the onus of effort is on them. On the other hand, there is a clear break between language as it was studied in the past and language as it is to be studied in the present. Frequently, alienation towards languages as they are taught at school has already started. The sudden reorienting can halt that process. In addition, the fact that all students (although the weaker ones probably exploit this more frequently) can use their 
knowledge in a science topic to understand and solve a linguistic problem without fully grasping the linguistic content (frequently the case in listening and reading) helps to bridge the gap between the perceived vital subjects and the less vital ones like languages. Obviously, practically it is not possible or even desirable to organize five years of study around LST. For this reason, once LST has been covered in sufficient depth, the curriculum is shifted back towards more general language. At no time, however is course content dedicated entirely to one aspect or the other. In addition, throughout the entire curriculum, the student experiences all of the differing approaches and techniques available to language learners, including the more traditional ones like grammar drilling and lab work. Thus, somewhere along a four to five year continuum, there is a pedagogical coat to fit the learner. In this way frustrations or dissatisfaction may be deviated either because the student is satisfied, or is content in the knowledge that he has been given what he asked for or will eventually receive it in time. In other words, an effort is made to serve up a pedagogical buffet on which everyone will find something satisfying. Consequently, over a period of time, the learner may modify his behaviour to the extent that language learning is seen as an accepted and important part of his training, if not an essential one.

\section{Generic pedagogy}

17 The act of making a full spectrum of language-learning content and techniques available to the students constitutes a form of generic pedagogy in that it guarantees a framework for success at some stage of learning: the learner is inevitably exposed to a learning situation that suits him. A generic pedagogy is one that has the potential to be applied to a wide variety of learning styles and approaches extending across many specializations. Its objectives are to increase learning efficiency, improve motivation and to forge new attitudes towards language learning. Ultimately, it may lead to a situation where autonomous learning and self-access become an accepted part of the curriculum in institutions like ESSTIN. But in the middle term is should generate constantly shifting curricula in which language learning approaches and techniques depend not on the authority (the language teacher) but on the client. The client will be active and not passive. There will be a balance between the pull of the learner and the push of the teacher. Finally, it will not be merely a question of picking the most recent commercial winner (CALL followed by multimedia, for example) but a question of exploiting the tools available as far as possible and according to whether they are suited to the learner.

The success of such an approach depends very much on where the language teacher's priorities lie. Is language teaching a question of implementing a curriculum whose efficiency and goals the teacher is convinced of? Or is it a question of offering a work plan with techniques that the learner is comfortable with? The answer must lie somewhere between the two, though where depends on who is perceived as the language specialist's client and, consequently, to whom she is answerable. Within institutions like ESSTIN it is difficult to have the learner accepted as the client. He is frequently perceived as someone who is told to do something, who doesn't do it and with whom one gets very annoyed for not having done it. But such attitudes on the part of teachers, whatever their discipline, can serve only to prolong the student's wait in the antechamber of adulthood. So the client is either the government who pays, via the institution and the relevant ministry, because they require certain subjects, including languages, to be taught, or the employer 
who needs employees with a certain type of knowledge. In a nutshell, we are juggling with three balls: government (the paymaster), employer (who has a need to satisfy) and student (who may be considered by some as a raw material to be transformed into a finished product). However, my conclusion is that the students are our clients because it is with them that we interact and through them that we satisfy the needs of the other two: value for money (government) and a finished product of quality (employer). Consequently, we are answerable to the students and place their needs first.

\section{Conclusion}

The above comments are based on observations made within a limited context. They are drawn only from the attitudes which may have an adverse effect on the learning of languages within a specific environment - viz ESSTIN. Positive attitude, and there are many, have not been taken into account here.

The question is can one generalise: do all trainee engineers have the same beliefs (and, therefore, attitudes) irrespective of the college they attend. Furthermore, what other factors, if any, come into play? The age/maturity of the learner surely has some bearing on his attitudes. His sociocultural background surely intervenes. The learning style imposed by the department, on the one hand, and by the college in all other disciplines, on the other hand, surely needs further consideration. All of these are constants, the effects of which have not been clearly defined.

21 Language specialists, in particular ones that find themselves in institutions that specialize in things other than languages, find themselves at a crossroads of differing and sometimes conflicting beliefs and values towards language learning. These constitute cultures at ESSTIN.

We constantly deal with the culture of the science teacher, the culture of the science student, the culture of the employer, and of course, the culture of the language specialist. Each, we know, has its own set of a priori and prejudices and each, within the encompassing framework of the institution or university or even the country, constitutes a sub-culture. It is the task of the language instructor, in particular those who are in isolation in engineering colleges, or perhaps schools of commerce or law schools and so on, to weave a path around the obstacles that crop up when dealing with attitudes that are foreign to them. We are, after all, travellers abroad. The path should lead to solutions based not on some academic theory of language learning which issues from one's own background and therefore culture and therefore prejudices, but to solutions that take as a starting point the culture of the client. The passage through is long and winding and the terrain is far from stable. 


\section{BIBLIOGRAPHY}

Berger, P. and Luckmann T. 1967. The Social Construction of Reality: A Treatise in the Sociology of Knowledge. New York: Anchor.

Gerth, H. and Mills C. 1947. From Max Weber: Essays in Sociology. New York: Oxford University Press. Carter, M. 1962. Home, School and Work. London: Pergamon.

Horowitz, I. 1965. The New Sociology. New York: Oxford University Press.

\section{NOTES}

1. These students usually have a "Bac C." Their attitude stems from beliefs about maths/physics and intelligence rooted in French culture.

\section{ABSTRACTS}

Institutions, including educational ones, invariably develop their own identity. It rests upon an institutional culture, a specific type of sub-culture with respect to society as a whole. This subculture will contribute considerably towards conditioning learners' attitudes to learning. Language teachers too are regulated by their own set of cultural beliefs and values. When both cultures confront each other, mutation, positive or negative, may take place either in the learner or in the teacher. Such mutation involves a reappraisal by one of the beliefs concerning the other. It is possible that generic pedagogy can bring about positive mutation and, therefore, guarantee language learning in the best possible conditions.

Toute institution, y compris dans le monde de l'éducation, a son identité propre. Cette identité repose sur la «culture de l'institution ", type secondaire de culture par rapport à la société dans son ensemble. Cette culture secondaire joue un rôle déterminant dans la formation des attitudes des apprenants. De leur côté, les professeurs sont eux aussi déterminés par leurs croyances et leurs valeurs culturelles. Lorsque ces deux ensembles culturels s'entrechoquent, il peut se produire une mutation, positive ou négative, chez l'apprenant comme chez le professeur. De telles mutations entraînent la reconsidération, par chacune des parties des valeurs de l'autre. Il n'est pas impossible que la pédagogie générique entraîne ce type de mutation positive, et favorise donc l'apprentissage d'une langue dans les meilleures conditions possible. 
INDEX

Mots-clés: attitude des apprenants, culture, mutation, pédagogie

Keywords: learners' attitude, pedagogy

\section{AUTHOR}

DAVID N. BROWN

David N. Brown teaches at ESSTIN - Université Nancy 1. david.brown@esstin.uhp-nancy.fr 